\title{
PENGEMBANGAN KONSEP ECOTOURISM PADA SENDANG DESA TEKERHARJO, KECAMATAN SOLOKURO, KABUPATEN LAMONGAN
}

\author{
Hammam Rofiqi Agustapraja ${ }^{1}$ \\ Program Studi Teknik Sipil, Fakultas Teknik, Universitas Islam Lamongan \\ Jln. Veteran No. 53 A Lamongan, 62211 \\ 0322324706 \\ hammamrofiqi@unisla.ac.id
}

\begin{abstract}
Economic inequality between cities and villages, this must be immediately prevented and minimized because it is an injustice in the economic field, therefore the government through village funds encourages villages to develop their existing potential, one of them is from the tourism sector, Takerharjo Village sees potential spring and spring as something more value that must be lifted and highlighted as an icon of a new tourist place managed by the village, it requires good planning, this study aims to provide recommendations on the Sendang arrangement concept in the village by using the concept of Ecotourism to plan the potential of spring and Takerharjo village springs became a village tourism icon, and also held a socialization on the importance of preserving the natural environment of the area so that the spring water source was maintained, with the aim that the spring and springs of Takerharjo Village could improve the welfare of the Takerharjo Village community.
\end{abstract}

Keywords : Sendang Desa, Potensi wisata, Ecotourism

\section{PENDAHULUAN}

Desa Takerharjo yang berada di Kecamatan Solokuro Kabupaten Lamongan Jawa Timur, mempunyai potensi alam yaitu sumber mata air, yang selalu mengeluarkan air walaupun memasuki musim kemarau, sumber tersebut tetap ada dan tidak mengalami kekeringan, sebaliknya pada waktu musim penghujan sumber air tesebut semakin banyak dan terkadang sampai meluber ke jalan dan masuk ke balai desa yang ada di depannya.

Melihat fenomena tersebut maka pihak desa dengan memanfaatkan dana desa, berencana ingin mengembangkan bahkan menata sumber air tesebut agar bisa dimanfaatkan lebih baik karena selama ini pemanfaatannya selama ini hanya digunakan untuk sumber air bersih dan sebagai pemandian umum, yang kurang terawat dengan baik, diharapkan dengan adanya penataan sendang (sumber air) tersebut, bisa menambah pemasukan desa dan dapat meningkatkan perekonomian masyarakat setempat dengan menjadikannya objek wisata baru.

Kondisi eksisting sendang / sumber air sekarang ini masih belum tertata dengan baik, dan hanya terbangun pagar tembok mengelilingi area sumber air, sumber air ini digunakan masyarakat sebagai sumber air bersih dan pemandian umum. Kondisi tersebut menyebabkan area sumber mata air terlihat angker, kotor dan tak terawat, bahkan kesadaran warga untuk merawat dan menjaganya dari sampah belum begitu baik.

Sendang / sumber air ini berada di tengahtengah pemukiman Desa Takerharjo, berhimpitan dengan batas rumah-rumah warga, hal ini juga perlu diadakan sosialisasi tentang sanitasi yang haik karena apabila tidak diadakan sosialisasi maka limbah rumah tangga akan mencemari sumber mata air ini, termasuk di dalamnya limbah cair deterjen, minyak, sabun mandi bahkan rembesan septic tank warga.
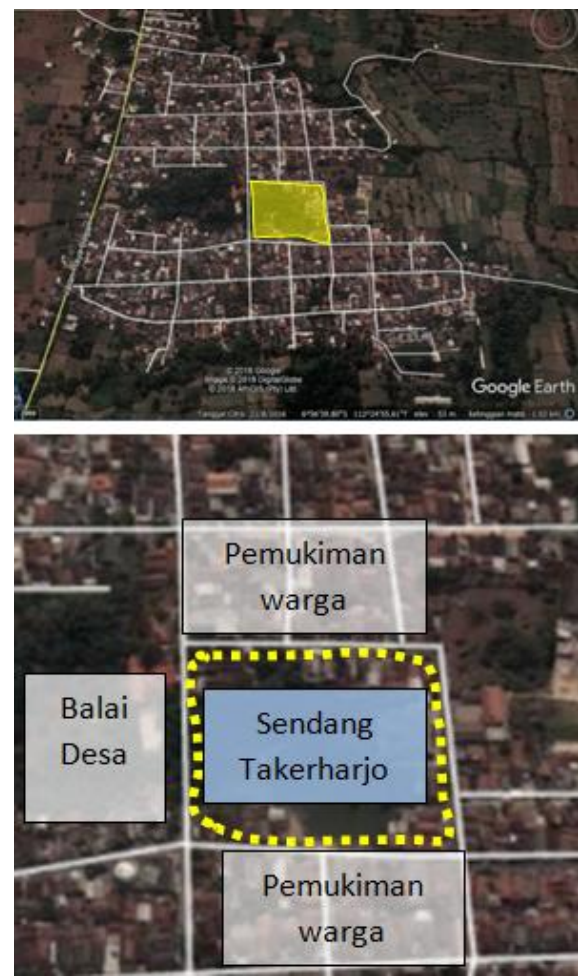

Gambar 1. Letak dan perbatasan Sendang Desa Takerharjo

Selain masalah sanitasi yang belum baik, daerah tersebut juga belum terdapat konservasi 
sumber mata air, dengan melestarikan dan menambah jumlah pohon, agar sumber mata air bisa tetap terjaga, mengingat fungsi pohon sebagai penyimpan air.

Disamping menata sendang / sumber air tersebut, Penelitian ini juga mengedukasi masyarakat untuk melestarikan lingkungan sekitar, terutama pohon-pohon besar yang menjadi sarana penyimpan air, mempertahankan yang sudah ada dan terlebih menambahkan jumlah pohon sehingga pelestarian sumber air bisa semakin terjaga.

Perumusan masalah pada Penelitian in didapatkan:

1. Bagaimana desain perencanaan dan penataan Sendang Desa Takerharjo agar dapat menjadi objek wisata baru?

2. Bagaimana desain perencanaan dan penataan Sendang Desa Takerharjo agar dapat melestarikan sumber air yang ada?

Tujuan dari Penelitian adalah sebagai berikut:

1 Memberikan sumbangsih ilmu dari segi arsitektural tentang perencanaan dan penataan Sendang agar bisa menjadi objek wisata baru

2 Mengolah tapak / lahan yang akan direncanakan menjadi lebih maksimal untuk digunakan sebagai objek wisata dan area konservasi sumber mata air sehinggabisa menambah pemasukan desa dan dapat meningkatkan perekonomian masyarakat

Terdapat beberapa padanan kata yang dapat digunakan untuk menyebut genangan air atau sumber air pada suatu tempat, berikut berikut beberapa padanan kata yang menyatakan genangan atau sumber air menurut Kamus Besar Bahasa Indonesia :

\section{a. sen.dang /sêndang/}

- $\quad n J w$ kolam di pegunungan dan sebagainya yang airnya berasal dari mata air yang ada di dalamnya, biasanya dipakai untuk mandi dan mencuci, airnya jernih karena mengalir terus; sumber air: gadis-gadis desa itu tiap pagi pergi ke -- untuk mengambil air minum

Dari penjelasan istilah-istilah di atas, maka kata sendang adalah kata yang tepat digunakan untuk yang menyatakan suatu tempat yang mempunyai air yang berasal dari mata air yang biasanya digunakan atau dimanfaatkan untuk kepentingan warga atau masyarakat sekitar.

\section{b. Wisata Desa}

Tujuan dari pengabdian masyarakat ini adalah untuk menjadikan sendang tersebut menjadi sebuat objek wisata yang mampu memberikan kontribusi terhadap peningkatan ekonomi masyarakat,

Wisata Desa terdiri dari dua suku kata yaitu wisata dan desa, menurut Kamus Besar Bahasa Indonesia $(\mathrm{KBBI})$ kata wisata memupunyai arti antara lain:

wi.sa.ta $v$ bepergian bersama-sama (untuk memperluas pengetahuan, bersenang-senang, dan sebagainya); bertamasya, $v$ piknik

Sedangkan pengertian desa menurut Kamus Besar Bahasa Indonesia (KBBI) mempunyai pengertian antara lain :

de-sa /desa/ $n$

1. kesatuan wilayah yang dihuni oleh sejumlah keluarga yang mempunyai system pemerintahan sendiri (dikepalai oleh kepala desa);

2. kelompok rumah di luar kota yang merupakan kesatuan: di - itu belum ada listrik;

3. udik atau dusun (dalam artian daerah pedalaman sebagai lawan kota);

4. $k l$ tanah, tempat, daerah;

Desa biasa juga disebut sebagai sebuah pemukiman, Permukiman Menurut Undang-Undang Nomor 4 Tahun 1992, adalah lingkungan hidup di luar kawasan lindung, baik kawasan perkotaan maupun perkotaan sebagai lingkungan hunian dan tempat kegiatan yang mendukung perikehidupan dan penghidupan. Dijelaskan lagi bahwa permukiman adalah gabungan 4 elemen pembentuknya (lahan, prasarana, rumah dan fasilitas umum) dimana lahan adalah lokasi untuk permukiman. Kondisi tanah mempengaruhi harga rumah, didukung prasarana permukiman berupa jalan lokal, drainase, air kotor, air bersih, listrik dan telepon, serta fasilitas umum yang mendukung rumah (Sinulingga 1999: 187 dalam Antariksa 2011);

Melihat pemilihan lokasi terbentuknya sebuah permukiman sebagai tempat tinggal tentunya memiliki beberapa alasan-alasan tersendiri, alasan tersebut tidak selalu terpaku pada kondisi rumah itu sendiri, tetapi lebih memperhatikan kelengkapan dari fasilitas kegiatan dan sosial di lingkungan tempat tinggal serta kemudahan aksesibilitasnya. Pola permukiman membicarakan sifat dari persebaran permukiman dengan kata lain pola permukiman secara umum merupakan suatu sifat berbeda dari hubungan faktor-faktor yang menentukan persebaran permukiman (Dwi Ari \& Antariksa 2005 : 79)

Dari dua pengertian di atas maka dapat disimpulkan bahwa wisata desa adalah kegiatan bersama-sama yang bertujuan untuk memperluas pengetahuan, bersenang-senang, dan sebagainya dengan tempat tujuan atau yang berlokasi di luar Kota, atau suatu tempat/wilayah yang mempunyai system peraturan sendiri baik itu dari norma, lingkungan, pmerintahan sendiri, jadi dalam berkegiatan berwisata desa harus memperhatikan norma-norma dan peraturan yang berlaku pada daerah tersebut.

\section{c. Ekowisata (Eco Tourism)}


The International Ecotourism Society (TIES) dalam Soedigdo (2013), menerangkan bahwa:

"Ecotourism is responsible travel to natural areas which conserved the environment and improves the welfare of local people."

Bahwa ekoturisme adalah bentuk atau konsep pariwisata yang mengedepankan konsevasi atau pelestarian terhadap lingkungan dengan cara mengajak serta masayrakat sekitar (lokal) sebagai pelaku, pemilik, penjaga dari kawasan wisata tersebut.

Page dan Dowling (2000) dalam Soedigdo (2013) meringkas konsep dasar ekowisata menjadi lima prinsip inti. Mereka termasuk yang berbasis alam, berkelanjutan secara ekologis, lingkungan edukatif, dan lokal wisatawan bermanfaat dan menghasilkan kepuasan.

a) Nature based (Berbasis alam), .

b) Ecologically sustainable (Berkelanjutan secara ekologis),

c) Environmentally educative (Pendidikan Lingkungan),

d) Locally beneficial (Manfaat bagi Masyarakat Lokal),

e) Generates tourist satisfaction (Menghasilkan kepuasan wisatawan),

Konsep Ecotourisme Village ini merupakan suatu upaya penataan kawasan kampung atau pedesaan yang mengedapankan segi lingkungan (Hildur, 2002). Dalam kegiatan penataan Sendang ini berbasis lingkungan mengedepankan pendekatan lingkungan agar sumber mata air bisa terus terjaga.

Variabel-variabel penelitian yang digunakan untuk menggolongkan ekoswisata yang tepat untuk diterapkan pada Sendang Desa Takerharjo dalam Soedigdo (2013) adalah sebagai berikut:

Tabel I. Ecotourism Opportunity Spectrum

\begin{tabular}{cllll}
\hline \multirow{4}{*}{ Parameter } & \multicolumn{3}{c}{ Spektrum Ekowisata } \\
\cline { 3 - 5 } & $\begin{array}{l}\text { Eco } \\
\text { Specia- } \\
\text { list }\end{array}$ & $\begin{array}{l}\text { Inter- } \\
\text { mediate }\end{array}$ & $\begin{array}{l}\text { Eco } \\
\text { General- } \\
\text { list }\end{array}$ \\
\hline \multirow{4}{*}{ Tingkat } & Sangat & Sulit, & Relatif \\
& Kesulitan & Sulit, & Air & Mudah, \\
& Akses & water & craft, & Jalan \\
& Trans- & ways, & Jalan & Raya \\
portasi & trail & Raya & \\
\cline { 2 - 5 } & Pemasar- & Pribadi & Setempa & Travel \\
an & eman & t, lokal & agen \\
\cline { 2 - 5 } & Sarana & Jalan & Kenda- & Kenda- \\
& Trans- & kaki, & raan & raan \\
portasi & kano, & ber- & ber- \\
& kuda & motor & motor
\end{tabular}

\begin{tabular}{|c|c|c|c|c|}
\hline & $\begin{array}{l}\text { Hubunga } \\
\mathrm{n} \text { Saluran } \\
\text { Informas } \\
\mathrm{i}\end{array}$ & $\begin{array}{l}\text { Tidak } \\
\text { Harmo } \\
\text { nis }\end{array}$ & $\begin{array}{l}\text { Tergant } \\
\text { ung } \\
\text { alam } \\
\text { dan pe- } \\
\text { ngemba } \\
\text { ngan }\end{array}$ & $\begin{array}{l}\text { harmoni } \\
\text { s }\end{array}$ \\
\hline \multirow{2}{*}{$\begin{array}{c}\text { Sumbe } \\
\text { r } \\
\text { daya }\end{array}$} & $\begin{array}{l}\text { Atraksi } \\
\text { yang } \\
\text { ditawark } \\
\text { an }\end{array}$ & $\begin{array}{l}\text { Ber- } \\
\text { orienta } \\
\text { si alam }\end{array}$ & $\begin{array}{l}\text { Fokus } \\
\text { pada } \\
\text { aspek } \\
\text { urban } \\
\text { dan } \\
\text { budaya }\end{array}$ & $\begin{array}{l}\text { Fokus } \\
\text { pada } \\
\text { aspek } \\
\text { urban } \\
\text { dan } \\
\text { budaya }\end{array}$ \\
\hline & $\begin{array}{l}\text { Pe- } \\
\text { ngemban } \\
\text { g-an } \\
\text { Visibilita } \\
\text { s }\end{array}$ & $\begin{array}{l}\text { Tidak } \\
\text { ber- } \\
\text { kemba } \\
\text { ng }\end{array}$ & $\begin{array}{l}\text { Hanya } \\
\text { di area } \\
\text { terpencil } \\
\text { Mengu- } \\
\text { tamakan } \\
\text { natura- } \\
\text { litas }\end{array}$ & $\begin{array}{l}\text { Ber-sifat } \\
\text { mo- } \\
\text { derat } \\
\text { Terus } \\
\text { ber- } \\
\text { kemban } \\
\text { g }\end{array}$ \\
\hline \multirow[t]{2}{*}{$\begin{array}{c}\text { Infra- } \\
\text { struktu } \\
\text { r }\end{array}$} & $\begin{array}{l}\text { Komplek } \\
\text {-sitas }\end{array}$ & $\begin{array}{l}\text { Tidak } \\
\text { rumit }\end{array}$ & $\begin{array}{l}\text { Tingkat } \\
\text { komplek } \\
\text { sitas } \\
\text { ber- } \\
\text { kemban } \\
\text { g }\end{array}$ & $\begin{array}{l}\text { Tingkat } \\
\text { komplek } \\
\text { sitas } \\
\text { ber- } \\
\text { kemban } \\
\text { g }\end{array}$ \\
\hline & fasilitas & $\begin{array}{l}\text { Tidak } \\
\text { ada } \\
\text { fasilita } \\
\text { s }\end{array}$ & $\begin{array}{l}\text { Akomod } \\
\text { asi } \\
\text { sederhan } \\
\text { a }\end{array}$ & $\begin{array}{l}\text { Hotel } \\
\text { dan } \\
\text { cottage }\end{array}$ \\
\hline \multirow[t]{2}{*}{$\begin{array}{l}\text { Interak } \\
\text { si } \\
\text { sosial }\end{array}$} & $\begin{array}{l}\text { Sesama } \\
\text { wisatawa } \\
\mathrm{n}\end{array}$ & $\begin{array}{l}\text { Sangat } \\
\text { minim }\end{array}$ & minim & sering \\
\hline & $\begin{array}{l}\text { masyarak } \\
\text { at lokal }\end{array}$ & $\begin{array}{l}\text { Sangat } \\
\text { minim }\end{array}$ & $\begin{array}{l}\text { Bertinda } \\
\mathrm{k} \\
\text { sebagai } \\
\text { inteprete } \\
\mathrm{r}\end{array}$ & $\begin{array}{l}\text { Bertinda } \\
\mathrm{k} \\
\text { sebagai } \\
\text { penyedi } \\
\text { a jasa }\end{array}$ \\
\hline $\begin{array}{l}\text { Tingka } \\
\mathrm{t} \\
\text { penget } \\
\text { ahuan } \\
\text { dan } \\
\text { ketera } \\
\text { mpilan }\end{array}$ & & $\begin{array}{l}\text { profesi } \\
\text { onal }\end{array}$ & terbatas & $\begin{array}{l}\text { Sangat } \\
\text { minim }\end{array}$ \\
\hline
\end{tabular}

\section{METODE}

Lokasi obyek wisata ini secara geografis terletak di Desa Takerharjo, Kecamatan Solokuro, Kabupaten Lamongan. Luas keseluruhan kawasan wisata ini adalah $\pm 2450 \mathrm{~m} 2$, dengan rincian sebagai berikut : Kolam air dengan sumber mata airnya dan lahan yang ditanami pohon-pohon besar,

Metode analisis data menggunakan paradigma penelitian deskriptif kualitatif berdasarkan teoriteori yang terkait. Menggunakan kata kunci ekowisata berbasis masyarakat

Teknik pengumpulan data yang akan dilakukan dalam penelitian ini dilakukan dengan beberapa cara: 


\subsection{Observasi}

Observasi dilakukan untuk mengetahui kondisi eksisting lingkungan sendang Desa Takerharjo, agar diketahui apa saja permasalahan yang terdapat pada lingkungan tersebut, termasuk di dalamnya masalah sanitasi, batas wilayah, vegetasi dan lingkungan masyarakat sekitar.

\subsection{Wawancara}

Wawancara dilakukan untuk menggali informasi yang mendalam tentang kondisi lingkungan dan permintaan dari mitra tentang perencanaan Sendang desa tersebut. Sehingga nanti keluaran dari gambar perencanaan sesuai dengan kebutuhan masyarakat Desa Takerharjo, dan disetujui untuk bersama-sama membangun dan merawat sumber air tesebut.

\subsection{Identifikasi Ekowisata}

Identifikasi Ekowisata ini dilakukan untuk mengidentifikasi kawasan Sendang / mata air tesebut termasuk dalam ekowisata yang mana sehingga dapat dijadikan arahan dalam pengembangan dan perencanaan sendang desa sebagai tempat wisata.

\section{PEMBAHASAN}

\subsection{Kondisi Wisata Desa Sendang Takerharjo}
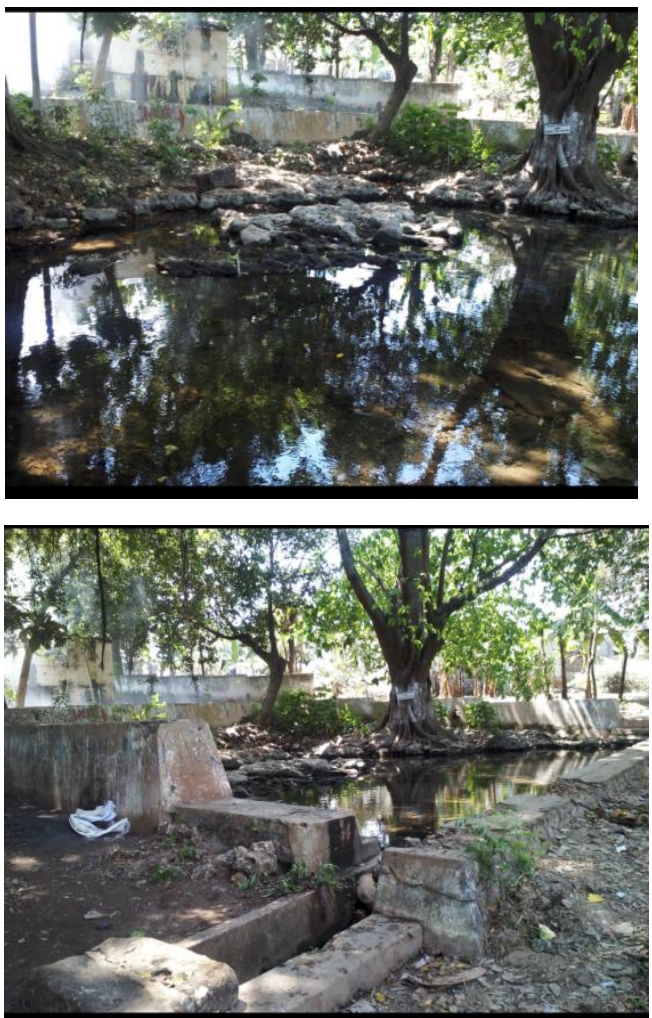
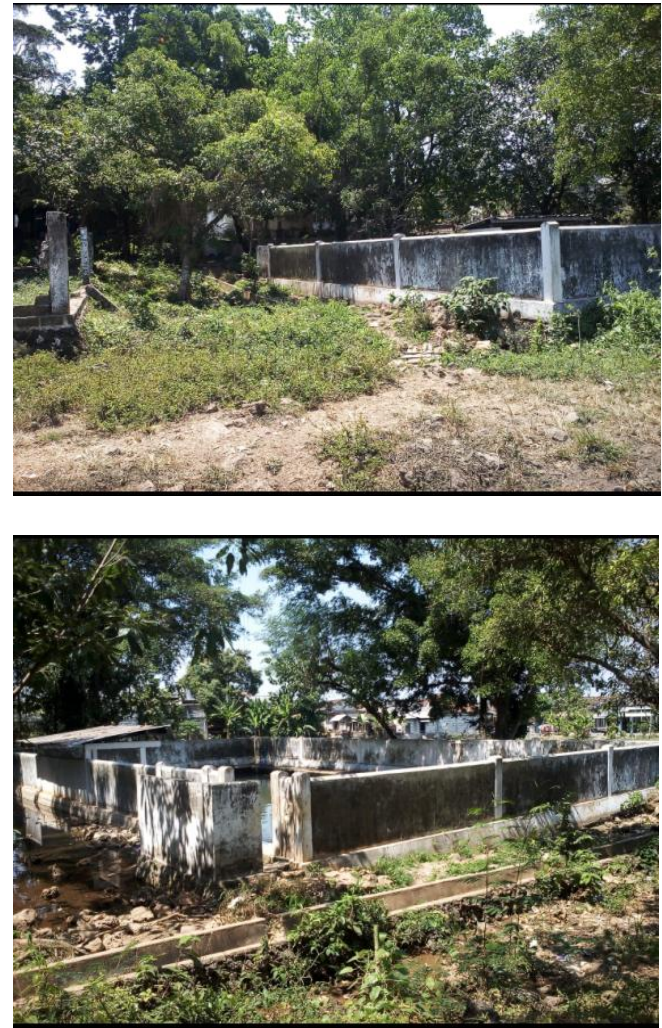

Gambar 2. Kondisi Eksisting Sendang Desa Takerharjo (2018)

Ada beberapa Kondisi di lapangan Sendang Desa Takerharjo yang memerlukan penanganan dan perhatian agar perencanaan objek wisata desa ini bisa berjalan dengan baik, kondisi tersebut antara lain:

1. Status legalitas. Kepemilikan Aset, termasuk batas wilayah Sendang yang akan direncanakan harus sudah ditetapkan, termasuk patokan dan tapal batas, biar kedepannya tidak menimbulkan konflik dengan pemilik lahan yang ada di sekitar sendang tersebut

2. Menentukan Batas Perkembangan Wisata Desa termasuk wilayah yang terdampak pada area sekitar sendang agar pengembangan objek wisata ini bisa diterima oleh semua kalangan masyarakat

3. Sarana prasarana. Sarana prasarana yang ada di Sendang Desa Takerharjo masih sangat minim dan sangat sederhana, sarana dan prasarana yang sebaiknya nanti dikembangkan untuk meningkatkan kunjungan wisata dapat mencakup toilet, tempat ganti baju, parkir, tempat sampah, perbaikan dan kenyamanan tempat dan lainnnya sehingga nantinya apabila diperbaiki dapat meningkat nilai dari lokasi tersebut. 
4. Aksesibilitas. Akses menuju sendang tersebut bisa dibilang cukup baik tetapi harus memerlukan pengembangan agar lebih baik lagi, letak sednang yang berada di tengahtengah desa, mengharuskan untuk dilakukan pemberian penanda di tepi jalan utama yang mampu membuat pengunjung bisa menemukan lokasi sendang tersebut.

5. Kesadaran lingkungan masyarakat cukup baik. Perlu adanya kampanye yang terus menerus untuk dapat menyadarkan masyarakat desa untuk menjaga lingkungan terutama kebersihan dan kelestarian sekitar Sendang agar sumber mata air bisa terus terjaga.

\subsection{Potensi Pengembangan Sendang Desa Takerharjo}

Dari pengamatan di lapangan Sendang Desa Takerharjo memiliki beberapa potensi untuk dikembangkan, potensi-potensi tersebut antara lain:

1. Lokasi yang Strategis. Lokasi Sendang berada di tengah-tengah desa sehingga mudah dijangkau oleh semua masyarakat Desa dan masarakat sekitar, hal tersebut juga didukung olhe kondisi sarana prasarana Desa yang cukup baik seperti jalan yang lebar sehingga memungkinkan kendaraan bisa lalu lalang menuju lokasi Sendang tersebut.

2. Sumber mata air yang tak pernah kering, desa tersebut memliki anugerah karena memiliki sumber mata air yang tak pernah kering, walaupun musim kemarau mata airnya juga tidak kering, hal ini juga dimanfaatkan untuk kebutuhan warga, bahkan kebutuhan seharihari bisa tercukupi dari sumber mata air ini.

\section{KESIMPULAN}

Rekomendasi dalam pengembangan Produk ekowisata Sendang Desa Takerharjo secara keseluruhan temasuk dalam spektrum Intermediate Ecotourism. Dalam hal ini pengembangan Sendang Desa tersebut dapat memberdayakan masyarakat Desa Takerharjo dalam menyediakan jasa dan pelayanan terhadap wisatawan dan juga sebagai pengelola objek wisata termasuk di dalamnya dari segi transportasi

Wisatawan-wisatawan yang berkunjung merupakan wisatawan domestik karena itu perlu adanya sosialisasi terhadap pelestarian lingkungan dalam hal ini untuk menjaga kebersihan, ketersediaan dan kelestarian pohon-pohon besar sebagai penampung air dan kelestarian mata air.

\section{PUSTAKA}

Agustapraja. Hammam R. 2011. Ruang Budaya pada Upacara Karo di Desa Ngadas, Tengger. Prosiding. Seminar Nasional 2011. The Local Tripod Akrab Lingkungan, Kearifan Lokal dan Kemandirian. Jurusan Arsitektur Fakultas Teknik Universitas Brawijaya. Malang

Antariksa. 2008. ArsitekturdanDimensiRuang. Dalam blog:http://antariksaarticle.blogspot.com/2008 /03/arsitektur-dan-dimensi-ruang.html

Antariksa. 2008.2 Massa danRuangdalamArsitektur.Dalam blog: http://antariksaarticle.blogspot.com/2008/03/ massa-dan-ruang-dalam-arsitektur.html

Antariksa, 2011.PengaruhKebudayaandanAdatIstiadatMas yarakatDalamPermukimanTradisional.Dalam blog:

http://antariksaarticle.blogspot.com/2011/02/p engaruh-kebudayaan-dan-adat-istiadat.html

Antariksa. 2011. StrukturRuangBudayaDalamPermukiman.Dalam blog:

http://antariksaarticle.blogspot.com/2011/01/s truktur-ruang-budaya-dalampermukiman.html

Antariksa.2011. PolaPermukimanTradisional.Dalam blog: Dalam blog: http://antariksaarticle.blogspot.com/2011/01/p ola-permukiman-tradisional.html

Antariksa. 2011. KearifanLokalMasyarakatSukuTengger: Dalam blog:

http://antariksaarticle.blogspot.com/2011/03/k earifan-lokal-masyarakat-suku-tengger.html

Direktorat Penelitian dan Pengabdian Kepada Masyarakat Direktorat Jenderal Pendidikan Tinggi Kemendikbud RI. 2017. Pedoman Penelitian Edisi XI.

Hendriks. 2002. The Ecological City-Impression. Netherlands: penerbit Aeneas Technical Publisher.

Jackson, Hildur. 2002. Ecovillage Living: Restoring The Earth and Her People. Penerbit Green Book

Mangunwijaya, Y.B. 1992. Wastu Citra Pengantar ke Ilmu Budaya Bentuk Arsitektur Sendi-Sendi Filsafatnya Beserta Contoh-Contoh Praktis. Jakarta: PT. Gramedia Pustaka Utama.

Ristianti, Novita Sari. 2015. Pengembangar 2 p Wisata Apung Kampung Nelayan 2 ir Balikpapan. RUANG (VOL.1) NO. 1, 2(1, נ, ו 40. Universitas Diponegoro Semarang

Rutherford, et all. 1994. The Ecological City: Preserving and Restoring Urabn Diversity. USA: The University of Massachutes Press.

Soedigdo, Doddy \& Priono, Yesser . 2013. PERAN EKOWISATA DALAM KONSEP 
PENGEMBANGAN PARIWISATA BERBASIS MASYARAKAT PADA TAMAN WISATA ALAM (TWA) BUKIT TANGKILING KALIMANTAN TENGAH. Jurnal Perspektif Arsitektur |Volume 8/No.2, Desember 2013

Sumalyo, Yulianto. 1997. Arsitektur Modern akhir abad XIX dan abad XX. Gadjah Mada University Press

Tjahjono, Gunawan. 2002. Arsitektur Indonesian Heritage. Jakarta: Jayakarta Agung Offset

Tai Chee Wong. 2011. Eco-City Planning: Policies, Practise and Design. New York:Penerbit Springer. 